\title{
Nutritional objectives for the Spanish population. Consensus from the Spanish Society of Community Nutrition
}

\author{
Lluís Serra-Majem ${ }^{1,2, *}$ and Javier Aranceta ${ }^{3,4}$, on behalf of the SENC Working Group on \\ Nutritional Objectives for the Spanish Population $†$ \\ 'Department of Clinical Sciences, University of Las Palmas de Gran Canaria, Spain: ${ }^{2}$ Chairman, Spanish Society of \\ Community Nutrition, Community Nutrition Research Center, Science Park of the University of Barcelona, C/Baldiri \\ Reixac 4-6, Torre D, 4A1, E-08028 Barcelona, Spain: ${ }^{3}$ Community Nutrition Unit, Municipality of Bilbao, Spain: \\ ${ }^{4}$ Department of Human Nutrition and Dietetics, University of Navarra, Spain
}

\begin{abstract}
The objective of this paper is to present the development of the Nutritional Objectives for the Spanish Population. Preparation of draft documents contributed by different working groups was followed by a consensus meeting held in Bilbao on 5-7 October 2000, hosted by the Spanish Society of Community Nutrition and sponsored by the World Health Organisation.

Establishing nutritional guidelines was conducted by: (1) analysing current food and nutritional data from nutritional surveys, for intermediate objectives; and (2) reviewing current scientific knowledge for final objectives.

The objectives include intermediate and ultimate figures, and comprise percentage of energy from macronutrients and fatty acids, fruit and vegetable consumption, frequency of sweets, physical activity and body mass index, folate, calcium, sodium, fluoride and iodine intake, dietary fibre, cholesterol, alcohol and duration of breastfeeding.

The nutritional objectives for the Spanish population create a rational framework for the development of dietary guidelines and nutritional policies in Spain, within a Mediterranean context.
\end{abstract}

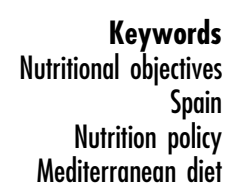

Since the beginning of the practice of medicine, the role of the diet as a potential therapeutic agent, as well as a causal factor in disease, has been recognised.

Physicians' and scientists' primary nutritional concerns until the middle of the twentieth century centred on the provision of sufficient energy and nutrients so as to meet vital requirements and alleviate or prevent deficiency diseases. Epidemiological studies carried out in the $1960 \mathrm{~s}$ and 70 s constituted the first solid basis for evidence that associated different dietary aspects with the initiation and development of coronary heart disease. In following years, the links continue to be consolidated between dietary patterns and many chronic diseases of widespread prevalence in developed societies. These findings have

†SENC (Spanish Society of Community Nutrition) Working Group on Nutritional Objectives for the Spanish Population: Lluís Serra-Majem (Chairman), Jose Mataix (Vice-Chair), Lourdes Ribas (Secretary), Javier Aranceta, José Banegas, Luis Bello, Alfonso Delgado, Alfredo Entrala, Juan Fernández-Ballart, Reina García-Closas, Jorge GomezAracena, Pilar Lainez, Gonçal Lloveras, José M Martín-Moreno, Joy Ngo, Rosa Ortega, Carmen Pérez-Rodrigo, Joan Quiles, Ana Requejo, Fernando Rodriguez-Artalejo, Emili Ros, Antoni Salvà, Gemma Salvador, Ana Sastre, Rafael Tojo, Josep Tur and Clotilde Vázquez. led to a change in the orientation of priorities in nutrition and public health programmes in Western countries. The subsequent evolution of nutritional epidemiology has shown the importance not only of quantitative dietary intake, but also of the structure, variety and other qualitative determinants of normal food consumption ${ }^{1-3}$.

Currently, the scientific community acknowledges that diet may contribute to the delaying or prevention of an important number of chronic diseases. It is also in agreement that promoting adequate eating habits, which follow healthy dietary models, constitutes one of the most important components within health promotion strategies.

The goal of food and nutrition policies is to facilitate, through specific strategies, an offering of nourishing foods so that the nutrient as well as social needs of a population are met. In order to achieve improvements in collective food intake, health authorities and/or scientific societies count on two tools of great strategic value in terms of public health: Nutritional Objectives and Food Guidelines, and more specifically, food guidelines based on country or regional food consumption patterns ${ }^{3,4}$. 


\section{Background in Spain}

In 1994 the Spanish Society of Community Nutrition (SENC), with the consensus of the Nutrition Unit of the European Regional Office of the World Health Organisation (WHO), developed Nutritional Objectives for the Spanish Population, which had some similarities to the WHO recommendations ${ }^{1,2}$. Food consumption habits of the population were taken into account in the moment of developing the Spanish guidelines. In our diet, the contribution of olive oil was found to be 13 to $20 \%$ of the energy consumed (depending on the region), which made it difficult to meet the recommendation to reduce fat intake to less than or equal to $30 \%$ of total calories. Therefore, SENC elaborated nutritional objectives that placed more emphasis on the quality rather than the quantity of dietary fats. Within the context of the Spanish Mediterranean diet, maintaining current levels of olive oil intake was promoted, establishing as an objective a reduction of $3-4 \%$ in saturated fatty acids (from 13\% currently to 10\%), and without setting strict objectives for total dietary fats (around 35\%). Food Guidelines for the Spanish Population were also concurrently developed, following a pyramid structure ${ }^{1,2}$.

Generally speaking, the establishment of nutritional objectives meant, until quite recently, setting a group of norms dealing with maximum population contributions of macronutrients, fatty acids, cholesterol and fibre. Nowadays, nutritional reference values (for vitamins and minerals) are often incorporated, as well as objectives for optimal food group intake, breast-feeding duration or suggestions for supplementation, physical activity or body mass index (BMI) intervals 5 . In this sense, SENC has revised and amplified the scope of their nutritional objectives, incorporating new areas of action.

\section{Diet, nutrition and health indicators in Spain}

Inadequate diets have an important health and social impact in Spain, and significant repercussions are noted in healthcare costs. Recent studies suggest that the incapacity associated with elevated intakes of saturated fats, and low consumptions of fruit and vegetables along with a sedentary lifestyle, would exceed smoking-induced health costs ${ }^{6,7}$. The variation in healthcare status is high between Autonomous Communities (CCAA) and between socio-economic groups in Spain, and has come to light in diverse mortality studies and analyses of morbidity using official registers. The consumption of fats, fruit and vegetables, dairy products, wine and alcohol, fish and meat, or the prevalence of obesity, for example, also vary considerably by Autonomous Community ${ }^{8-11}$. These factors are less homogeneous than other variables such as tobacco consumption or physical inactivity. As such, in our country diet and nutrition represent the main sources of variability in the geographic distribution of health indicators related to non-infectious diseases, together with socio-economic and cultural factors. For this reason, in Spain, nutrition should be considered as a priority when public health objectives attempt to reduce geographical inequalities in health status ${ }^{7,12}$.

To date, dietary habits in Spain play a role in certain deficiency diseases, mainly in iodine deficiency ${ }^{13}$ and, to a lesser degree than in other European countries, iron deficiency anaemia ${ }^{14}$. Moreover, other nutritional deficits related to folate and vitamin D can also be detected, among others ${ }^{7}$. However, nutrition plays a decisive role in the increased risk of certain chronic diseases, such as energy and fat consumption and their relationship to obesity, salt and hypertension, and saturated fat and coronary heart disease ${ }^{7}$. In addition, oxidative balance is an important contributor to many degenerative diseases, on which nutrition has a catalysing effect via mechanisms still not completely known to us.

A sedentary lifestyle, whose relationship to energy balance is critical, also acts as an important risk factor that should be considered in the prevention of nutritionrelated conditions such as obesity. In light of progressively decreasing energy requirements, on the other hand, we are obliged to gradually reduce dietary energy intake, leading to concomitant decreases in vitamin and mineral contributions.

\section{Nutritional objectives and population-based food guidelines}

In 1992 the International Nutrition Conference (INC) of the Food and Agriculture Organisation (FAO)/WHO called for the identification and implementation of strategies and actions that would improve nutritional status and food intake throughout the world. Above all, the intent of the ICN's plan of action was to disseminate nutrition information, employing sustainable strategies based on food consumption ${ }^{3}$.

In 1995, an FAO/WHO consulting group was formed on the topic of Food-Based Dietary Guidelines (FBDG). This group has recently published a report in which it recommends the identification of potential target foods in public health nutrition programmes. This could be achieved through food consumption analysis in those with high or low intakes of a target or priority nutrient (saturated fats, fibre, etc.) or via other analyses of actual food and nutrient intakes. The report specifically recommends that FBDG should be established 'on what can realistically be achieved based on a given socio-economic context, rather than an intent to eliminate in one single step, the difference between current and desirable or ideal intakes'. For this reason, irrespective of whether the intakes are desirable or ideal, they must be drawn from population-based epidemiological studies. As such, for the elaboration of FBDG, it is essential to analyse prevalent food consumption patterns, thus developing 
Table 1 Nutritional Objectives for the Spanish Population: Consensus of the Spanish Society of Community Nutrition

\begin{tabular}{|c|c|c|}
\hline & Intermediate nutrition objectives ${ }^{a}$ & Final nutrition objectives ${ }^{b}$ \\
\hline 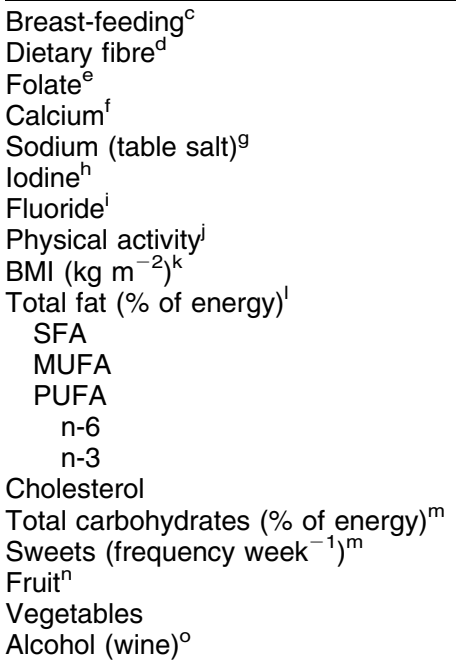 & $\begin{array}{l}4 \text { months (exclusive) } \\
>22 \mathrm{~g} \mathrm{day}^{-1} \\
>300 \mu \mathrm{g} \mathrm{day}^{-1} \\
\geq 800 \mathrm{mg} \mathrm{day}^{-1} \\
<7 \mathrm{~g} \mathrm{day}^{-1} \\
150 \mu \mathrm{gday}^{-1} \\
1 \mathrm{mg} \mathrm{day}^{-1} \\
\Uparrow \mathrm{No} \text { information } \\
<25 \\
\leq 35 \% \\
\leq 10 \% \\
20 \% \\
5 \%\end{array}$ & 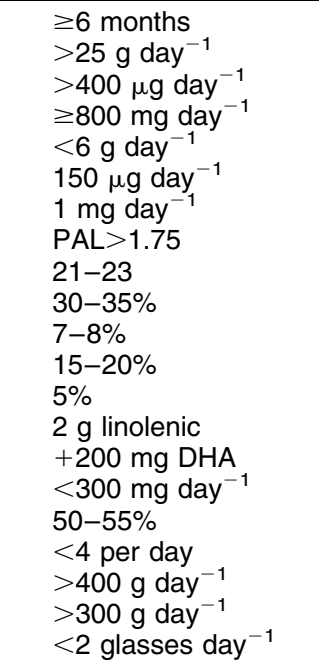 \\
\hline
\end{tabular}

${ }^{a}$ Corresponds basically to the 75 th or 25 th percentile, depending on the findings (favourable or unfavourable) of population-based nutrition studies carried out in Spain, or, when referring to micronutrients, to nutrient reference values. To be evaluated by the end of 2005.

${ }^{b}$ Final nutrition objectives, in accordance with current scientific evidence and based on nutrient reference values. To be evaluated by the end of 2010 .

${ }^{c}$ Breast-feeding rates in Spain have been estimated to be as low as $23 \%$ and $11 \%$ at 3 and 6 months, respectively, compared with $85 \%$ and $73 \%$ in Sweden, or 33\% and $21 \%$ in the United Kingdom. Thus Spain has one of the lowest prevalences of breast-feeding in Europe, particularly after the second month from delivery. It is necessary to implement breast-feeding promotion programmes not only among pregnant women, but also among paediatricians, obstetricians and maternity ward staff ${ }^{18}$

${ }^{d}$ Fibre intake in Spain is low despite the elevated consumption of fruit and vegetables. The decrease in cereal intake in general, and in the form of whole grains in particular, makes it necessary to increase current average fibre consumption (with levels being the lowest in the Canary Islands, Catalonia, Andalusia and the Northern part of the Peninsula) to greater than $25 \mathrm{~g}^{19-25}$.

e Folate consumption in Spain is quite low and inadequate with respect to the Recommended Nutrient Intake (RNI). Major differences in intake are seen between Autonomous Communities, which are linked to fruit and vegetable consumption, with the Canary Islands Extremadura and Murcia having the lowest levels and Catalonia having the most adequate ${ }^{19-25}$.

${ }^{f}$ Corresponds to RNI for adult population, but intakes should be greater in several population subgroups such as infants and adolescents, pregnant, lactating and menopausal women and in the elderly.

$\mathrm{g}$ Table salt intake has decreased in Spain in the past few decades, which has been offset, however, by recently increased consumption of certain prepared foods with an elevated salt content. The decrease in cerebrovascular morbidity and mortality linked to the control of hypertension in Spain is one of the most significant public health achievements in recent years ${ }^{10}$.

${ }^{\mathrm{h}}$ lodine intake in the form of iodised salt has increased in Spain; however, the issue is not completely resolved as some zones of mild deficiency still exist in a number of Autonomous Communities ${ }^{13}$.

SENC does not support the generalised application of fluoridated water in public utilities for reasons of cost-effectiveness. Nevertheless, it does promote the optimisation of fluoride intake through tablets, bottled water with high fluoride content and salt fortified with fluoride and iodine.

${ }^{j}$ It is difficult to estimate the magnitude of sedentary lifestyles in Spain. Nonetheless, it is calculated that at least $60 \%$ of the adult population is sedentary during leisure hours. Physical activity levels (PALs) have decreased drastically in the last 50 years in Spain, with an age-associated reduction of more than $500 \mathrm{kcal}^{-1} \mathrm{from}^{-1}$ frome age 20 to 60 years ${ }^{19,20,24}$.

$\mathrm{k}$ The average body mass index in the Spanish adult population is estimated to be $25.5 \mathrm{~kg} \mathrm{~m}^{-2}$, which has been translated into an intermediate objective of less than $25 \mathrm{~kg} \mathrm{~m}^{-2}$. This corresponds with the 40th percentile. The prevalence of obesity continues to be on the increase in Spain, thus constituting one of the main public health problems, affecting more than $13 \%$ of the adult population ${ }^{8}$. ' The mean fat intake in Spain is approximately $38 \%$ of total calories, with $12.5 \%$ in the form of saturated fats; intermediate objectives are 35 and $10 \%$ (ultimate $30-35 \%$ and less than 10\%) corresponding with the 25th percentile ${ }^{16}$. The mean intake of monounsaturated fatty acids (MUFAs) is approximately $20 \%$ of total calories, and that of polyunsaturated fatty acids (PUFAs) $6 \%$. SENC considers as adequate a total fat intake of $35 \%$ of total calories, which could be achieved by reducing saturated fatty acids (SFAs) from $12.5 \%$ to $10 \%$ and maintaining the elevated percentage of monounsaturates. Dietary cholesterol should decrease in tandem with reduced saturated fat intake, even though its significance and priority are not comparable. DHA - docosahexaenoic acid.

$\mathrm{m}$ The contribution of carbohydrates in the Spanish diet should reach around $50-55 \%$ of total calories, thus facilitating a total fat intake of $35 \%$, of which, as previously mentioned, $20 \%$ would be provided in the form of MUFAs. Should physical activity levels of the population increase, a higher level of fat intake would be justified. However, since levels are quite sedentary, carbohydrate-rich diets are preferred. Considerable controversy exists as to whether sugar as a percentage of calories should be quantified ${ }^{26,27}$. SENC, in concurrence with the conclusions of other workgroups ${ }^{26}$, has opted not to quantify but rather qualify the limitation of sugar and sugar-containing products. In agreement with the aetiopathogenesis of dental caries ${ }^{28}$, it was decided to restrict the frequency of consumption of sweets to less than four times a day ${ }^{6}$. This would obligate the determination of this qualitative variable in epidemiological studies.

$n$ Fruit and vegetable consumption varies greatly from one Autonomous Community to the next, with Catalonia, Aragón, Castilla-La Mancha and Navarra and La Rioja having the highest intakes and the Canary Islands, Extremadura, Asturias and Cantabria the lowest. The difference in intake between Communities was found to be more than $100 \mathrm{~g}$ day ${ }^{-1}$. The total average intake of fruit and vegetables should reach around $550 \mathrm{~g} \mathrm{day}^{-1}$ in the short-to-mid term and greater than $700 \mathrm{~g}^{2}$ day $^{-1}$ in the long term ${ }^{19-25}$.

- Wine consumption also reflects clear regional variation, showing a moderate North (high intakes) to South (low intakes) gradient. Madrid, Castilla-La Mancha, Extremadura, Comunidad Valenciana, Murcia, Andalusia and the Canary Islands have consumption levels of less than $40 \mathrm{ml}$ per day ${ }^{19-25}$. Wine consumption should not be generalised as a public health strategy, as part of its beneficial effects can be obtained from grapes and their must. Additionally, alcohol consumption may compromise health under given circumstances (driving, pregnancy, addiction). However, moderate wine consumption is considered permissible if limited to 250$400 \mathrm{ml} \mathrm{day}^{-1}$, and if taken with meals. For women, consumption levels should be somewhat lower. 
food guidelines that are appropriate and realistic for the population. In this respect, the definition of a prudent diet should be based on actual knowledge regarding nutrition, health and disease. Most importantly, it should be founded on the analysis of food consumption in subgroups of the population that most closely approximate the nutritional ideal, after having prioritised nutritional problems at the community level, with the intent that one part of the population learns from the other ${ }^{3,15,16}$.

One of the objectives of the EURODIET project, financed by the European Union, was to develop a generic framework for the elaboration of food guidelines in member countries, as well as its implementation with the support of the formulation of global action strategies $^{17}$. This approach would permit not only the development of realistic food guidelines within a reasonable time frame, but also the setting of short-term and intermediate nutritional objectives.

\section{Nutritional Objectives for the Spanish Population: SENC Consensus (2000)}

Table 1 outlines the Nutritional Objectives for the Spanish Population, based on a consensus meeting of SENC that took place in October 2000 in Bilbao, sponsored by WHO. Intermediate and final or ultimate nutrition objectives were defined at this time.

SENC chose to carry out a consumption analysis of macro- and micronutrients utilising data from the principal nutrition studies conducted in Spain. This allowed for quantification of the value corresponding to the 75th percentile for nutrients targeted for increased intake. For nutrients for which intakes were to be reduced, the 25 th percentile was applied. These values constitute SENC's intermediate nutritional objectives, which reflect reachable goals within our context given that $25 \%$ of the Spanish population is already meeting the nutrient objectives.

Final nutritional objectives encompass long-term goals and are based on the best scientific evidence available at the present time within the context of the EURODIET project, with incorporated pertinent adaptations to the Mediterranean reality and idiosyncrasy in Spain ${ }^{6}$.

\section{References}

1 Aranceta J. Objetivos nutricionales para la población española. In: Serra Majem L, Aranceta Bartrina J, Mataix Verdú J, eds. Documento de Consenso Guias Alimentarias para la Población Española. Barcelona: SG-Editores, 1995; $127-52$

2 Serra Majem L, Aranceta J, Group of Nutrition Guidelines of the Spanish Society of Community Nutrition. Nutrition and dietary guidelines for the Spanish population. Tool for a nutrition policy in Spain. In: Wheelock V, ed. Implementing Dietary Guidelines for Healthy Eating. London: Chapman \& Hall, 1997; 233-44.
3 Food and Agriculture Organisation/World Health Organisation (FAO/WHO). Preparation and Use of Food-Based Dietary Guidelines. Report of a joint FAO/WHO consultation. Technical Report Series No. 880. Geneva: WHO, 1998.

4 Serra Majem L, Aranceta J. Guías alimentarias, educación nutricional, fortificación y suplementación. In: Galvez R, Sierra A, Saenz C, Gomez I, Fernández-Crehuet J, Salleras L, et al., eds. Medicina Preventiva y Salud Pública, 10th ed. Barcelona: Masson, 2000; 923-34.

5 Wheelock V, ed. Implementing Dietary Guidelines for Healthy Eating. London: Chapman \& Hall, 1997.

6 Kafatos A, Corrington A, eds. Eurodiet Reports and Proceedings [special issue]. Public. Health Nutr. 2001; 4(2A): $265-436$.

7 Serra-Majem Ll, Santana JF, Salmona E. Dietary habits and nutrient status in Spain. World. Rev. Nutr. Diet. 2000; 87: $127-59$.

8 Aranceta J, Pérez Rodrigo C, Serra Majem L, Ribas L, Quiles Izquierdo J, Vioque J, Foz M, Grupo Colaborativo Español para el Estudio de la Obesidad. Prevalencia de obesidad en España: estudio SEEDO'97. Med. Clin. (Barc.) 1998; 111(12): 441-5.

9 Rodriguez Artalejo F, Guallar-Castillon P, Gutierrez-Fisac JL, Ramon Banegas J, del Rey Calero J. Socioeconomic level, sedentary lifestyle, and wine consumption as possible explanations for geographic distribution of cerebrovascular disease mortality in Spain. Stroke 1997; 28(5): 922-8.

10 Banegas JR, Perez-Regadera AG, Rodriguez-Artalejo F. Hypertension control as an indicator of the geographical variation of stroke. Stroke 1998; 29(4): 867-8.

11 Rodriguez Artalejo F, Guallar-Castillon P, Banegas Banegas JR, Manzano BA, del Rey Calero J. Consumption of fruit and wine and the decline in cerebrovascular disease mortality in Spain (1975-1993). Stroke 1998; 29(8): 1556-61.

12 Serra-Majem L, Ferro-Luzzi A, Bellizzi MC, Salleras L. Nutrition policies in Mediterranean Europe. Nutr. Rev. 1997; 55(Suppl. II): s42-s57.

13 Serra-Majem L, Lloveras G, Vila L, Salleras L. Estrategias para la prevención y el control de los trastornos ocasionados por la deficiencia de yodo en Catalunya (1983-1992). Endocrinología (Barc.) 1993; 40: 273-7.

14 Arija V, Fernández Ballart J, Salas Salvadó J. Carencia de hierro y anemia ferropénica en la población española. Med. Clin. (Barc.) 1997; 109: 425-30.

15 Gibney MJ, Serra-Majem Ll, Kearney JM, Becker W, Löwik $\mathrm{MRH}$, Wiseman $\mathrm{M}$, et al. Por una política de nutrición en Europa en el siglo XXI: desarrollo de unas guías alimentarias basadas en el consumo de alimentos. Nutr. Clin. 2000; 20: $111-28$.

16 Williams C, Wiseman M, Buttriss J, eds. Food-based dietary guidelines - a staged approach [special issue]. Br. J. Nutr. 1999; 81(Suppl. 2): S29-S153.

17 Kafatos A, Codrington CA. Nutrition and diet for healthy lifestyles in Europe: the Eurodiet Project. Public Health Nutr. 1999; 2(3A): 327-8.

18 Yngve A, Sjöstrom M. Prevalence of breast-feeding in Europe. Public. Health. Nutr. 2001; 4: 1353-5.

19 Serra Majem L, Ribas L, García Closas R, Ramon JM, Salvador G, Farran A, et al. Libre Blanc: Avaluació de l'Estat Nutricional de la Població Catalana (1992-93). Barcelona: Departament de Sanitat i Seguretat Social, Generalitat de Catalunya, 1996; 1-252.

20 Aranceta J, Pérez C, Eguileor I, et al. Encuesta Nutricional del País Vasco. Vitoria: Gobierno Vasco, 1990.

21 Aranceta J, Pérez C, Amela C, García Herrera R. Encuesta Nutricional de la Comunidad de Madrid. Madrid: Consejería de Salud de Madrid, 1994.

22 Violan C, Stevens L, Molina F. Encuesta de Alimentación en la Población Adulta de Murcia 1990. Serie Informes No. 7. 
Murcia: Consejería de Sanidad, Dirección General de Salud. Región de Murcia, 1992.

23 Arija V, Salas-SalvadóJ, Fernández-Ballart J, Martí-Henneberg C. Consumo, hábitos alimentarios y estado nutricional de la población de Reus (IX). Evolución del consumo de alimentos y de su participación en la ingesta de energía y nutrientes y su relación con el nivel socioeconómico y cultural entre 1983 y 1993. Med. Clin. (Barc.) 1996; 106: 174-9.

24 Serra-Majem L, ed. Evaluación del estado nutricional de la población Canaria (1997-98) [special issue]. Arch. Latinoam. Nutr. 2000; 50(Suppl. 1): 1-72.
25 Mataix J, ed. Encuesta de Nutrición de Andalucía (1997). Sevilla: Junta de Andalucía, 2001.

26 Expert Consultation Group, FAO/WHO. Carbohydrates in Human Nutrition. Publication 66. Rome: FAO, 1999.

27 Ruxton CHS, Garceau FJS, Cottrell RC. Guidelines for sugar consumption in Europe: is a quantitative approach justified? Eur. J. Clin. Nutr. 1999; 53: 503-13.

28 García Closas R, Serra Majem L. Contribución de la epidemiología a la evaluación del poder cariogénico de la dieta. Rev. en Sal. Pub. 1997; 5: 49-68. 